\title{
Long non-coding RNAs in lung cancer: Regulation patterns, biologic function and diagnosis implications (Review)
}

\author{
LIN JIANG $^{1-3}$, ZHENG LI $^{2-4}$ and RANRAN WANG ${ }^{1}$ \\ ${ }^{1}$ Department of Cardiovascular Surgery, The Second Xiangya Hospital, Central South University, Changsha, Hunan 410011; \\ ${ }^{2}$ The Key Laboratory of Carcinogenesis of The Chinese Ministry of Health, School of Basic Medical Sciences; \\ ${ }^{3}$ The Key Laboratory of Carcinogenesis and Cancer Invasion of The Chinese Ministry of Education, Cancer \\ Research Institute, Central South University; ${ }^{4}$ High Resolution Mass Spectrometry Laboratory of \\ Advanced Research Center, Central South University, Changsha, Hunan 410078, P.R. China
}

Received March 1, 2019; Accepted July 16, 2019

DOI: $10.3892 /$ ijo.2019.4850

\begin{abstract}
Lung cancer is the most common malignancy with the highest mortality worldwide. Emerging research has demonstrated that long non-coding RNAs (lncRNAs), a key genomic product, are commonly dysregulated in lung cancer and have significant functions in lung cancer initiation, progression and therapeutic response. IncRNAs may interact with DNA, RNA or proteins, as tumor suppressor genes or oncogenes, to regulate gene expression and cell signaling pathways. In the present review, first a summary was presented of the causal effects of dysregulated lncRNAs
\end{abstract}

Correspondence to: Dr Ranran Wang, Department of Cardiovascular Surgery, The Second Xiangya Hospital, 139 Middle Renmin Road, Changsha, Hunan 410011, P.R. China

E-mail: wangranran001@csu.edu.cn

Abbreviations: lncRNA, long noncoding RNA; NSCLC, non-small lung cancer; SCLC, small cell lung cancer; OCT4, organic cation/carnitine transporter 4; TDP43, TAR DNA-binding protein 43; PSF, PTB-associated splicing factor; SR, serine/arginine splicing factor; MALAT1, metastasis associated lung adenocarcinoma transcript 1; HOTAIR, HOX transcript antisense RNA; H19, imprinted maternally expressed transcript; PVT1, plasmacytoma variant translocation 1; ANRIL, antisense non-coding RNA in the INK4 locus; DLX6-AS1, DLX6 antisense RNA 1; SCAL1, lung cancer associated transcript 1; SOX2OT, SOX2 overlapping transcript; ZXF1/ACTA2-AS1, ACTA2 antisense RNA 1; PANDAR, promoter of CDKN1A antisense DNA damage activated RNA; BANCR, BRAF-activated noncoding RNA; SPRY4-IT1, SPRY4 intronic transcript 1; PICART1, P53-inducible cancer-associated RNA transcript 1; MIR22HG, MIR22 host gene; DNMT1, DNA methyltransferase 1; DNMT3b, DNA methyltransferase 3 $\beta$; MEG3, maternally expressed 3; UCA1, urothelial cancer associated 1; GAS5, growth arrest specific 5; MRP1, multidrug resistance-associated protein 1; MDR1, multidrug resistance 1; EGFR-TKIs, epidermal growth factor receptor tyrosine kinase inhibitors; $\mathrm{BaP}$, benzo(a)pyrene

Key words: long non-coding RNA, lung cancer, tumorigenesis, metastasis, drug resistance, regulation patterns and mechanism in lung cancer. Next, the function and specific mechanisms of lncRNA-mediated tumorigenesis, metastasis and drug resistance in lung cancer were discussed. Finally, the potential roles of lncRNAs as biomarkers for lung cancer were explored.

\section{Contents}

1. Introduction

2. Regulation patterns of dysregulated lncRNAs in lung cancer

3. Biologic functions and molecular mechanisms of lncRNAs in lung cancer

4. IncRNAs as biomarkers in lung cancer

5. Conclusion and perspectives

\section{Introduction}

According to the 2018 cancer statistics, it was estimated that 234,030 cases of lung and bronchus cancer were newly diagnosed in the United States (1). Lung cancer is the primary cause of cancer-related deaths worldwide and results in $>1.3$ million deaths per year (2). Lung cancer mainly includes non-small cell lung cancer (NSCLC) and small cell lung cancer (SCLC). NSCLC constitutes $85 \%$ of all lung cancer cases, including lung adenocarcinoma, squamous cell carcinoma and large cell lung cancer (3-5). The lung cancer incidence rate is increasing worldwide, especially female morbidity (6). Despite the discovery of multiple mutations and targeted drugs, such as for the genes epidermal growth factor receptor (EGFR), KRAS and MET, the prognosis of advanced lung cancer patients remains poor, with a 5-year survival rate stagnant at $\sim 5 \%$ (7). Known risk factors, such as smoking habits, air pollution and genetic variations, have an important impact on lung cancer development and clinical outcomes (8).

Long non-coding RNAs (lncRNAs) are 200 nt in length, lack the protein coding potential, and constitute $\sim 70 \%$ of the non-coding RNAs $(9,10)$. Except for their role as competing endogenous RNA (ceRNA) to sponge microRNAs (miRNAs), lncRNAs have also been shown to interact with DNA, RNA and various proteins, thereby having crucial roles in diverse 
physiological and pathological functions (11). Appropriate lncRNA expression is essential for normal cell function and is precisely regulated by epigenetic mechanisms and various other molecules. Recent reports have found that dysregulation of IncRNA expression induces tumorigenesis, invasiveness and drug resistance through diverse mechanisms in multiple types of cancer $(12,13)$. IncRNAs are also important, complex controlling factors in the pathogenesis of lung cancer (14-17). In the present review, the behavior and environment-induced dysregulation of IncRNA expression was summarized in regards to lung cancer, their functions and molecular mechanisms were examined, and their potential as biomarkers for the diagnosis and prognosis of lung cancer was explored.

\section{Regulation patterns of dysregulated IncRNAs in lung cancer}

Many large-scale investigations, including microarray profiling and deep sequencing data, have revealed that the derangement of IncRNA expression is a primary feature in lung cancer initiation and progression $(18,19)$. The lncRNA expression levels are precisely regulated in the physiological state and are potentially disturbed in the pathological state by diverse mechanisms. The influence of chemical compounds and the local tumor microenvironments responsible for the regulation of lncRNA expression should not be ignored. Additionally, the function of epigenetic modification in tumor progression is likely involved. Abnormal epigenetic regulation can lead to aberrant activation of lncRNAs without involving any changes in the DNA sequences. Various transcription factors can bind within the promoter regions of IncRNAs to activate or inhibit their transcription. These regulation patterns of dysregulated lncRNAs in lung cancer are summarized in Fig. 1 and Table I.

Chemical compounds and hypoxia. It has been reported that H19 is significantly elevated in the airway epithelium of healthy 20 pack-year smokers compared with non-smokers (20). Mineral dust-induced gene (Mdig) is associated with environmental exposure to smoke and dust, which influences the progression of lung cancer. Mdig regulates the expression of $\mathrm{H} 19$ by regulating the levels of trimethylated histone 3 lysine 9 (H3K9me3) at the promoter region of H19 (21). Benzo(a)pyrene (BaP) increases $\mathrm{H} 19$ expression and its interaction with the S-adenosylhomocysteine hydrolase protein. By contrast, H19 knockdown suppresses the formation of benzo(a)pyrene-7,8-dihydrodiol-9,10-epoxide (BPDE)-DNA adducts, which decreases the risk for lung cancer (22). Smoke-associated and cancer-associated lncRNA-1 (SCAL1) is located on the chromosome 5q14.3 locus. High expression of SCAL1 in lung cancer cells is induced by cigarette smoke extract. SCAL1 is upregulated by nuclear factor erythroid 2-related factor 2 (NRF2) and serves a functional role in cytoprotection against cigarette smoke-induced toxicity. These findings suggest that SCAL1 has an important role in the antioxidant pathway (23).

Hypoxia induces upregulation of the lncRNA metastasis-associated lung adenocarcinoma transcript 1 (MALAT1) in lung cancer (24). Hypoxia-inducible factor $1 \alpha$ (HIF-1 $\alpha$ ) can bind to the hypoxia-sensitive elements on the promoter region of HOX transcript antisense RNA (HOTAIR) and activate the transcription of HOTAIR, as well as promote NSCLC proliferation and metastasis under hypoxia conditions (25).

Epigenetic modification. The methylated levels of MALAT1 promoter are low in lung cancer cells or tissues. Treatment with the methyl donor, S-adenosylmethionine, suppresses MALAT1 expression in lung cancer cells (26). In such cases, the IncRNA sprouty RTK signaling antagonist 4 intronic transcript 1 (SPRY4-IT1), located at chromosome 5q31.3, is upregulated and promotes proliferation and metastasis of cancer cells (27). However, SPRY4-IT1 is expressed at low levels in NSCLC tissues and inhibits the proliferation and epithelial-mesenchymal transition (EMT) of NSCLC cancer cells. Enhancer of zeste homolog 2 (EZH2) can directly bind to SPRY4-IT1 and silence its transcription in NSCLCs $(28,29)$.

Transcription regulation. $\mathrm{p} 53$ has been shown to bind the promoter region of HOTAIR and suppress its transcription. By contrast, HOTAIR enhances H3K27me3 modification within the $\mathrm{p} 53$ promoter and inhibits $\mathrm{p} 53$ expression in the lung cancer cell line A549. This negative feedback loop of HOTAIR-p53 promotes the progression of lung cancer (30). On the contrary, p53 increases expression of p21-associated non-coding RNA DNA damage-activated (PANDAR), which is a tumor suppressor gene that is downregulated in human NSCLC tissues (31). PANDAR can interact with nuclear transcription factor Y subunit $\alpha$ (NF-YA) and low expression of PANDAR increases NF-YA binding to the promoter of $\mathrm{B}$ cell lymphoma-2 (Bcl-2); this leads to an increase in $\mathrm{Bcl}-2$ expression, thereby inhibiting NSCLC cell apoptosis (32). Binding of c-Myc to the E-boxes near the $\mathrm{H} 19$ imprinting control region activates the transcription of H19 in lung cancer (33). Notably, c-Myc also binds to the E-box element upstream of antisense ncRNA in INK4 locus (ANRIL) and induces its expression in NSCLC cells (34). The transcription factors, c-Myc and Yin Yang 1 (YY1), can activate transcription of the IncRNA plasmacytoma variant translocation 1 (PVT1), by binding to its promoter region in lung cancer $(35,36)$. The transcription factor, specificity protein 1 (SP1), promotes MALAT1 transcription and MALAT1 directly binds to SP1 protein to enhances its stability. This MALAT1-SP1 positive feedback loop has been demonstrated to promote the progression of lung cancer (37). Octamer binding transcription factor 4 (OCT4) has been reported to increase MALAT1 transcription by binding to its promoter enhancer region, thereby inducing upregulation of MALAT1 expression in lung cancer (38). MALAT1 expression has also been shown to be regulated by TAR DNA-binding protein 43 (TDP43) in lung cancer (39).

\section{Biologic functions and molecular mechanisms of In- cRNAs in lung cancer}

In lung cancer progression, abnormally regulated lncRNAs act as vital factors to regulate the gene signaling network at the transcriptional, post-transcriptional and post-translational level, and thus, alter various malignant behaviors and treatment responses of lung cancer (Table II).

Proliferation and survival. MALAT1 can act as a ceRNA to regulate miR-124/STAT3 and miR-206/AKT expression to 


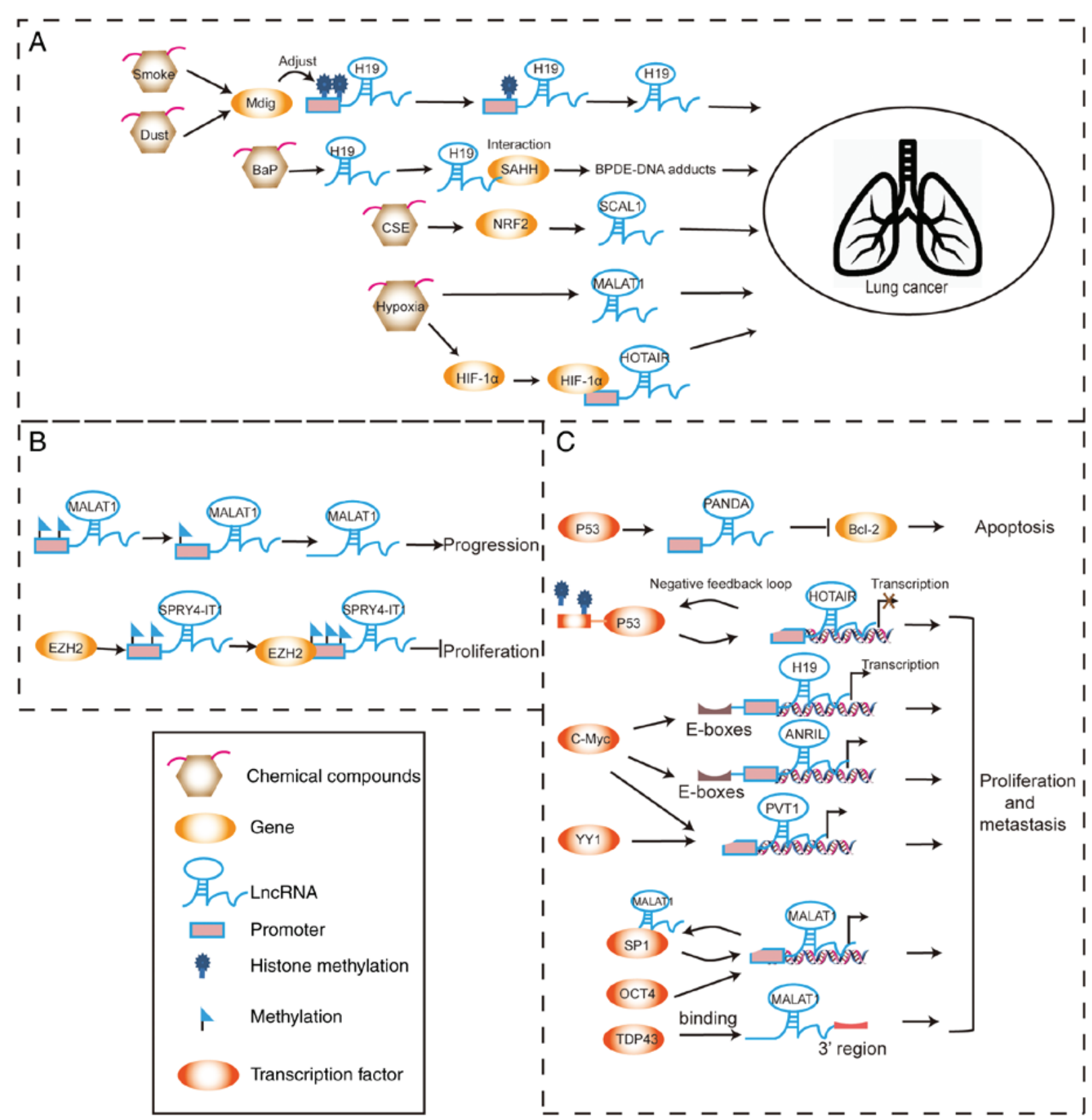

Figure 1. Schematic plot of regulation patterns of dysregulated lncRNAs in lung cancer. (A) Chemical compounds and hypoxia affect lncRNA expression to promote cancer progression. (B) Changes in epigenetic modification of IncRNAs can regulate the development of lung cancer. (C) Various transcription factors can interact with lncRNAs to activate or inhibit their transcription, subsequently affecting cancer progression. IncRNA, long non-coding RNA.

promote NSCLC progression $(40,41)$. MALAT1 binds with serine/arginine splicing factor (SR) in the nuclear speckle domains and increases SR phosphorylation followed by regulation of the alternative splicing of pre-mRNA (42). MALAT1 suppresses p53 activity by binding to a minimal region of p53 promoter that regulates downstream genes influencing the cell cycle progression of lung cancer cells (43). Downregulation of MALAT1 has been shown to inhibit NSCLC progression by inhibiting autophagy (44). The 5'end of HOTAIR binds with the polycomb repressive complex 2 (PRC2) resulting in histone $\mathrm{H} 3$ being trimethylated at lysine 27, while the 3 'domain binds to the histone demethylase complexes (lysine demethylase 1A/REST corepressor 1/RE1 silencing transcription factor) facilitating histone $\mathrm{H} 3$ lysine 4 demethylation, which causes homeobox D cluster (HOXD) gene silencing (45). Silencing of HOTAIR decreases miR-326 expression, which regulates paired like homeobox $2 \mathrm{~A}$ (Phox2a) and inhibits tumor cell proliferation and migration in lung cancer (46). H19 knockdown evidently restrains NSCLC cell proliferation (47-49). Notably, H19 functions as a ceRNA sponge for miR-17 to modulate signal transducer and activator of transcription 3 (STAT3) expression (50), and as a ceRNA sponge for miR-484 to regulate the expression of Rho associated coiled-coil containing protein kinase 2 (ROCK2) (51), thereby promoting lung cancer development. Finally, H19 sponges miR-196b to elevate LIN28B expression, which accelerates the proliferation of lung cancer cells (52).

Another intergenic non-coding RNA, LINC00473, has been demonstrated to be the most upregulated lncRNA in liver kinase B (LKB1)-inactivated NSCLC tissues. 
Table I. Molecules and chemical compounds that regulate lncRNA expression in lung cancer.

\begin{tabular}{lllc}
\hline IncRNA & \multicolumn{1}{c}{ Expression } & \multicolumn{1}{c}{ Regulation } & $($ Refs.) \\
\hline MALAT1 & Upregulation & $\begin{array}{l}\text { Hypoxia induces MALAT1; SAM suppresses MALAT1; SP1, OCT4 } \\
\text { and TDP-43 promote MALAT1 transcription }\end{array}$ & $(24,26,37,38)$ \\
HOTAIR & Upregulation & HIF-1 $\alpha$ activates HOTAIR; P53 suppresses HOTAIR expression & $(25,30)$ \\
H19 & Upregulation & MDIG and benzo(a)pyrene increase H19 expression; c-Myc increases & $(21,22,33)$ \\
& U19 transcription & $(35,36)$ \\
PVT1 & Upregulation & MYC and YY1 increase PVT1 transcription & $(34)$ \\
ANRIL & Upregulation & C-Myc increases ANRIL transcription & $(23)$ \\
SCAL1 & Upregulation & Cigarette smoke extract increases SCAL1; NRF2 upregulates SCAL1 & $(31)$ \\
PANDAR & Downregulation & P53 increases PANDAR expression; & $(28,29)$ \\
SPRY4-IT1 & Downregulation & EZH2 silences SPRY4-IT1 transcription &
\end{tabular}

LINC00473 interacts with non-POU domain-containing octamer-binding protein(NONO) and subsequently facilitates NONO/CREB regulated transcription coactivator 1 (CRTC1) interaction and CREB-mediated transcription, to promote the proliferation of LKB1-inactivated NSCLC cells (53). Another IncRNA, DLX6-AS1, is located on the chromosome 7q21.3 and has been found to be upregulated in lung adenocarcinoma tissues comparted with adjacent normal tissues (54). DLX6-AS1 alters JAK/STAT signaling to promote proliferation of lung adenocarcinoma cells (54). Another study demonstrated that the knockdown of ANRIL induced cell cycle arrest at the G1/G0 phase and promoted cell cycle apoptosis (34). In addition, depletion of ANRIL increased p15 expression and induced cell-cycle arrest at the G2/M phase of lung cancer cells (55). Knockdown of ANRIL has been found to reduce EZH2 binding with Krüppel-like factor 2 (KLF2) and p21 promoter, and to also inhibit the proliferation of PC9 NSCLC cells (56). SOX2 overlapping transcript (SOX2OT) is encoded on chromosome $3 \mathrm{q} 26.3$ locus, and has been found to be upregulated in $53.01 \%$ of NSCLCs and significantly associated with poor survival in patients lung cancer. Thus, silencing of SOX2OT can suppress cell proliferation by causing $\mathrm{G} 2 / \mathrm{M}$ arrest via regulation of EZH2 expression (57).

Similarly, BRAF-activated non-protein coding RNA (BANCR) is an antitumor lncRNA of $693 \mathrm{bp}$, located on the chromosome 9q21.11 (58). Knockdown of BANCR induces p38 mitogen-activated protein kinase (MAPK) and JNK activation, which promotes lung cancer cell proliferation and migration (59). By contrast, other IncRNAs, such as p53 inducible cancer associated RNA transcript 1 (PICART1), can inhibit JAK2/STAT3 signaling to suppress lung cancer proliferation and induce apoptosis (60). Another IncRNA, MIR22 host gene (MIR22HG), also has a tumor suppressive role in lung cancer, by inhibiting oncogenes Y-box binding protein 1 (YBX1) and MET, while increasing p21 expression (61). The IncRNA chromatin-associated RNA 10 (CAR10) can regulate the expression of neighboring genes, which was first confirmed in human fibroblasts (62). Previous studies have shown that CAR10 can act as an oncogene by binding to the transcription factor YBX1 and subsequently increase the proliferation of lung cancer cells (63). A schematic illustrating the aforementioned lncRNAs and their roles in proliferation of lung cancer cells is shown in Fig. 2.

Invasion and metastasis. Liu et al (64) reported that MALAT1 was upregulated in NSCLC tissues with bone metastasis compared with non-metastatic NSCLC. In addition, MALAT1 downregulation inhibited the metastasis of lung cancer cells and upregulated the expression of the metastasis-suppressor genes MIA SH3 domain ER export factor 2 (MIA2) and roundabout guidance receptor 1 (ROBO1), whereas it decreased the expression of the tumor promoter genes glypican 6 (GPC6), adhesion G protein-coupled receptor L2 (LPHN2), and AT binding cassette subfamily A member 1 (ABCA1) (65). Furthermore, MALAT1 acts as a sponge for miR-204 and enhances the expression of Snail family transcriptional repressor 2 (SNAI2, also known as SLUG), to promote epithelial-mesenchymal transition and migration of lung cancer cells (66). MALAT1 silencing can decrease the migration and invasion ability of cells by inhibiting the expression of C-X-C motif chemokine ligand 5 (CXCL5) $(26,39)$. MALAT1 can cause the dissociation of PTB-associated splicing factor (PSF) from the promoter region of the proto-oncogene $\mathrm{G}$ antigen 6 (GAGE6), which promotes the proliferation and invasion of A549 cells (24).

HOTAIR also promotes the invasion and metastasis of lung cancer cells by regulating homeobox A5 (HOXA5), miR-613 and 14-3-3o expression (67-69). Ono et al (70) found that patients with elevated expression of HOTAIR were more prone to lymph node metastasis and recurrence. HOTAIR interacts with lymphoid-specific helicase (HELLS) and affects the forkhead box A (FOXA) 2/FOXA1 expression ratio, thereby promoting invasion and migration of lung adenocarcinoma cells (71). PVT1 has been shown to regulate miR-497 expression and to competitively bind with miR-200a and miR-200b, to upregulate matrix metalloproteinase 9 (MMP9) expression and promote the metastasis of $\operatorname{NSCLC}(72,73)$. ANRIL suppression has been shown to inhibit the invasion and migration of lung tumor cells (74,75). LINC00963 is highly expressed in NSCLC tissues and interacts with phosphoglycerate kinase (PGK1) to prevent its ubiquitination, leading to activation of the AKT/mTOR oncogenic signaling pathway. In addition, LINC00963 interacts with NONO to 


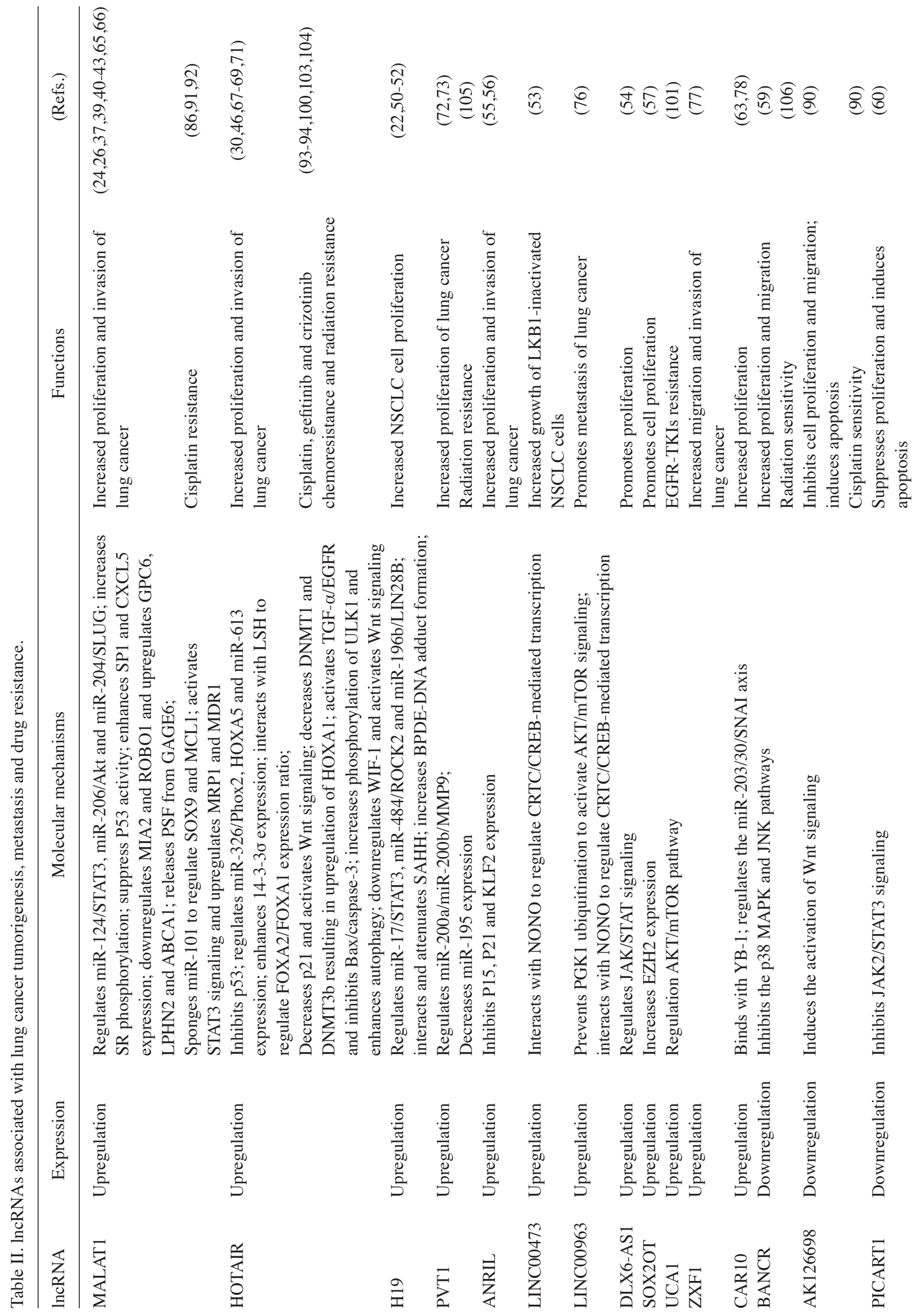


activate CRTC/CREB-mediated transcription promoting the metastasis of lung cancer cells (76). Knockdown of the lncRNA ACTA2 antisense RNA 1 (ACTA2-AS1, also known as ZXF1) inhibits the invasion and migration of lung cancer cells (77). Finally, Ge et al found that CAR10 acted as a ceRNA for miR-30 and miR-203 and induced EMT by regulating Snail family transcriptional repressor 1 (SNAI1) and SNAI2 expression (78). A schematic illustrating the aforementioned lncRNAs and their roles in invasion and metastasis of lung cancer cells is shown in Fig. 3.

Drug and radiation resistance. Medical treatment for lung cancer mainly includes platinum-based chemotherapy and molecular-targeted drugs, such as epidermal growth factor receptor tyrosine kinase inhibitors (EGFR-TKIs) $(79,80)$. However, drug resistance at many instances leads to failure of treatment $(81,82)$. Previous studies have shown that multidrug resistant (MDR) A549/DDP cells were primarily caused by changes to the cell membrane transporters, abnormal target enzymes and irregular apoptosis pathway (83-85). In recent years, there has been evidence that some lncRNAs are also involved in the drug resistance mechanism of lung cancer (Fig. 4).

The levels of several lncRNAs, including MALAT1, H19 and HOTAIR, have been demonstrated to be upregulated in cisplatin-resistant lung cancer (86-88), whereas maternally expressed 3 (MEG3) and AK126698 are downregulated in drug-resistant A549/DDP lung cancer cells $(89,90)$. MALAT1 acts as a ceRNA to sponge miR-101 and then regulates SRY-box transcription factor 9 (SOX9) and MCL1 to enhance cisplatin resistance $(91,92)$. Furthermore, MALAT1 induces cisplatin resistance via STAT3 activation, and upregulation of multidrug resistance-associated protein 1 (MRP1) and multidrug resistance 1 (MDR1) expression (86). HOTAIR increases cisplatin resistance in A549 cells by decreasing p21 expression and activating the Wnt signaling pathway (93). HOTAIR upregulates HOXA1 by decreasing the expression of DNA methyltransferase (DNMT) 1 and DNMT3b, resulting in chemoresistant SCLC $(94,95)$. By contrast, MEG3 expression is decreased in cisplatin-resistant A549/DDP lung cancer cells and cisplatin-insensitive lung adenocarcinoma tissues (89). Overexpression of MEG3 has been reported to mediate re-sensitization to cisplatin in drug resistant A549/DDP cells and animal models (89). MEG3 affects cisplatin sensitivity partially via regulation of the p53 and $\mathrm{WNT} / \beta$-catenin signaling pathways (89). AK126698 is also found at high expression levels in DDP-sensitive A549 cells compared with the drug resistant A549/DDP cells. As a result, AK126698 knockdown has been demonstrated to decrease the apoptosis of A549 cells following cisplatin treatment via activation of Wnt signaling (90).

EGFR-TKIs are used to treat NSCLC patients with EGFR mutations (96-98). When comparing gefitinib-sensitive to gefitinib-resistant human lung cancer cells, 1,731 lncRNAs were found to be upregulated and 2,936 lncRNAs downregulated in drug resistant cell lines (99). HOTAIR induces gefitinib resistance by activating transforming growth factor (TGF)- $\alpha$ /EGFR signaling and inhibiting the Bax/caspase-3 pathway (100). Similarly, urothelial cancer associated 1 (UCA1) expression is increased in lung cancer 


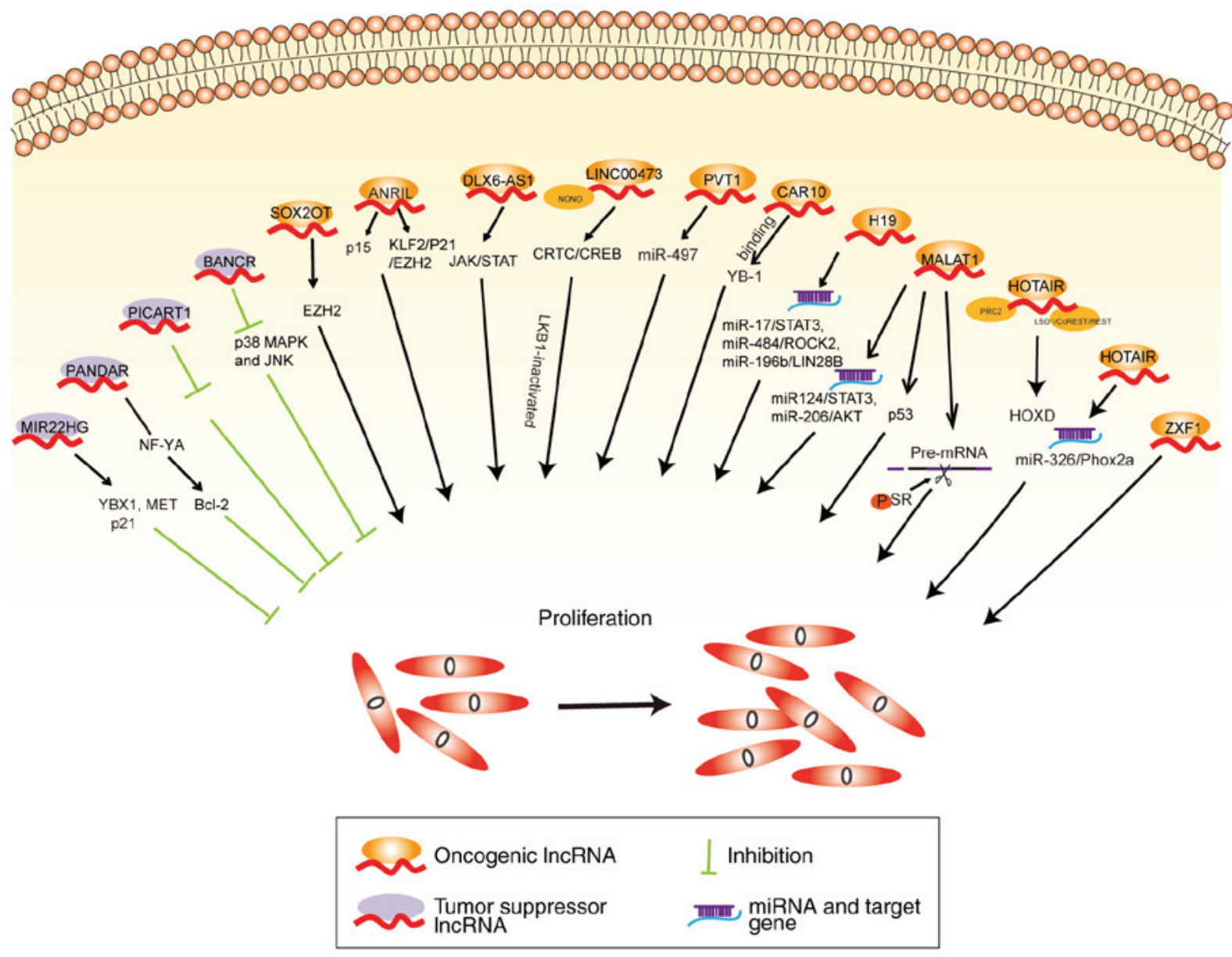

Figure 2. Roles of IncRNA-mediated regulatory pathways in proliferation of lung cancer cells. According to their functions, lncRNAs were classified into two categories: Oncogenic lncRNAs (orange) are upregulated in lung cancer, enhancing growth and proliferation of lung cancer cells; whereas tumor suppressor lncRNAs (purple) are downregulated in lung cancer, inhibiting proliferation. lncRNA, long non-coding RNA.

patients with EGFR-TKI resistance and thereby affects patient prognosis. Knockdown of UCA1 retrieves gefitinib sensitivity in drug-resistant cells not harboring an EGFR T790M mutation, via regulation of the AKT/mTOR pathway (101). Additionally, upregulation of growth arrest-specific 5 (GAS5) has been detected in EGFR-TKI sensitive lung cancer cells. GAS5 enhances the sensitivity of lung cancer cells to EGFR-TKIs by regulating the EGFR pathway and insulin-like growth factor 1 receptor (IGF-1R) (102). Finally, crizotinib is an inhibitor of receptor tyrosine kinases and is mainly used for ALK positive lung cancer patients (79). HOTAIR increases crizotinib resistance of NSCLC cells via enhancing the phosphorylation of ULK1 and stimulating autophagy (103).

In addition, HOTAIR increases the radiation resistance in lung cancer via downregulation of Wnt inhibitory factor 1 (WIF-1) and activation of the Wnt signaling pathway (104). Similarly, PVT1 also decreases the radiosensitivity of NSCLC cells via sponging of miR-195 (105). BANCR was demonstrated to be highly expressed in Lewis lung tumor-bearing mice after radiation therapy (106). Knockdown of BANCR expression promoted cancer cell viability after radiation therapy, and mice with lower BANCR expression had larger tumor sizes (106). These studies could help predict which patients may best respond to radiotherapy.

\section{IncRNAs as biomarkers in lung cancer}

lncRNAs have complex roles in the initiation and progression of lung cancer, thereby affecting the prognosis of patients. IncRNAs are prevailing in the plasma with relative stability, which is suitable for early diagnosis of lung cancer. Recently, abundant lncRNAs have also been detected in serum exosomes with specific and characteristic expression markers in patients with lung cancer, suggesting that they could be utilized as potential clinical biomarkers.

Several reports have found that increased HOTAIR levels in patients with lung cancer and upregulation of HOTAIR expression correlates with the pathological staging and poor prognosis of lung cancer $(107,108)$. Plasma HOTAIR expression levels could be a biomarker for the diagnosis and monitoring of NSCLC patients (109). Similarly, H19 is upregulated in NSCLC tissues and negatively correlated with the survival of lung cancer patients $(21,49)$. PVT1 has been shown to be overexpressed in NSCLC tissues, and elevated PVT1 expression levels have been demonstrated as an independent prognostic factor for NSCLC (110-112). Wu et al (110) reported that PVT1 was also overexpressed in lung squamous cell carcinoma. Notably, overexpression of the 1ncRNA ZXF1, positioned at chromosome 10q23.31 with a length of 3,985 bp, was found to be significantly related 


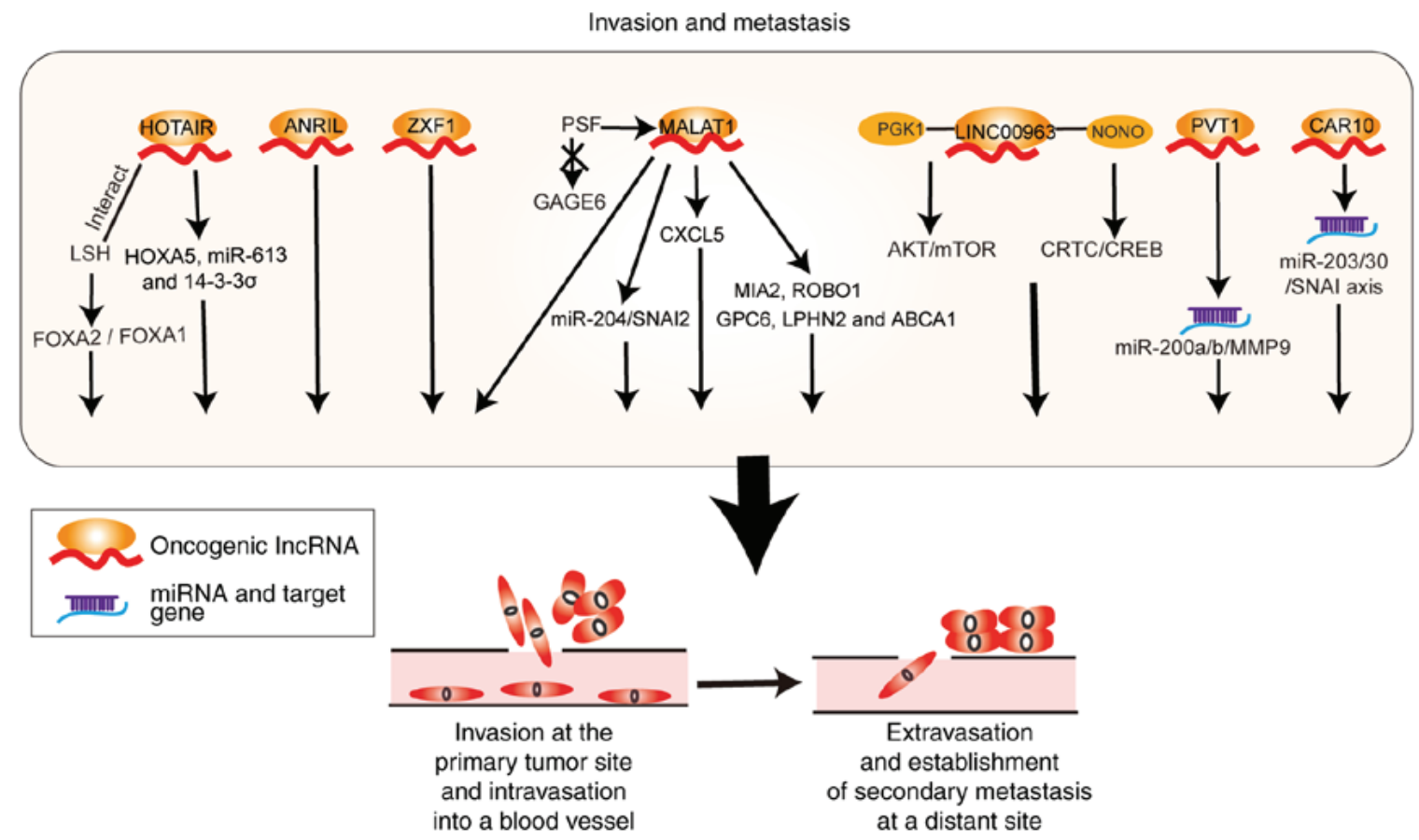

Figure 3. Roles of lncRNA-mediated regulatory pathways in invasion and metastasis of lung cancer. IncRNAs act as sponges for miRNAs or regulate their downstream target genes, thereby promoting invasion and metastasis of lung cancer cells. lncRNA, long non-coding RNA; miRNA, microRNA.

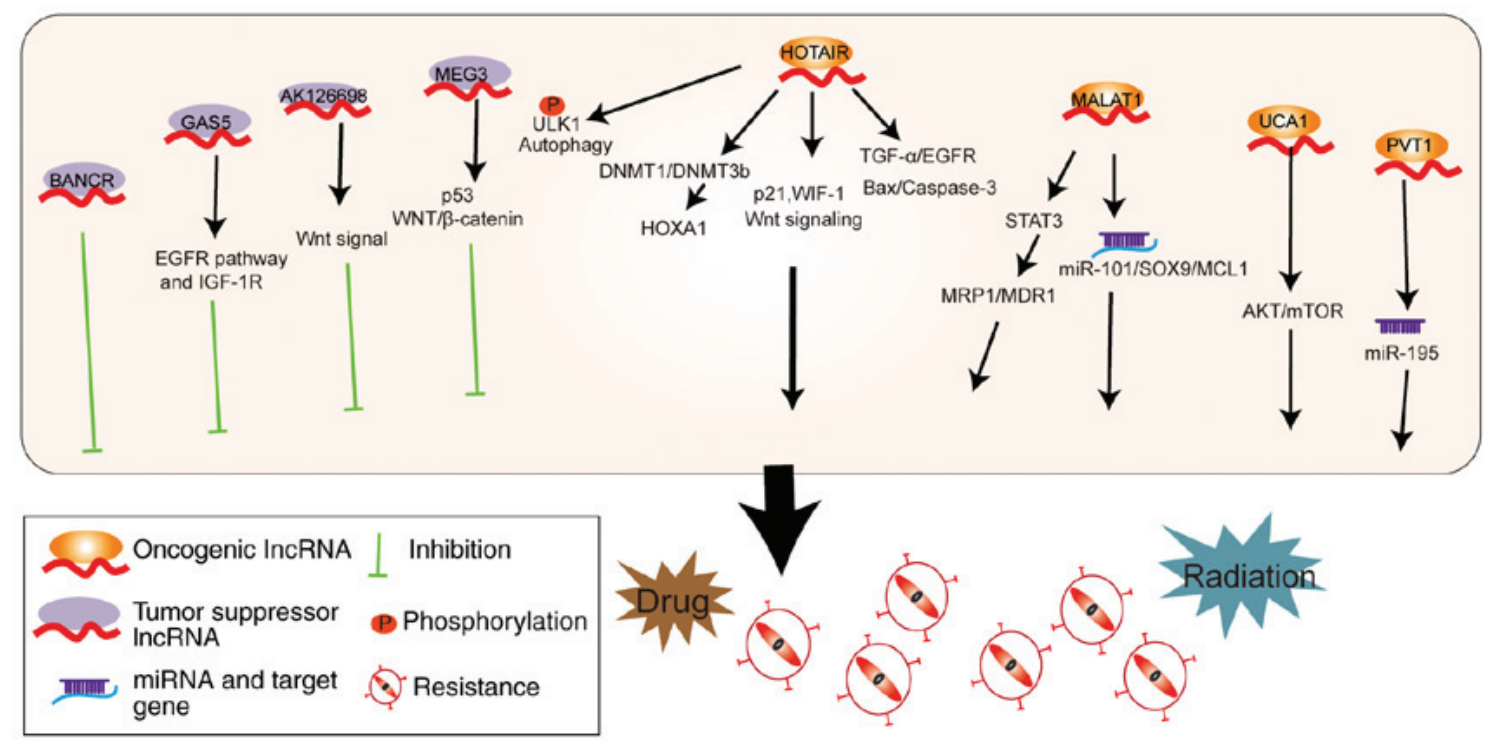

Figure 4. IncRNAs mediate drug and radiation resistance. Tumor suppressor lncRNAs can regulate EGFR, IGF-1R, the Wnt signaling pathway and p53 to inhibit resistance of cancer cells towards drug and radiation therapy. Oncogenic lncRNAs promote resistance via multiple pathways, target genes and miRNAs. lncRNA, long non-coding RNA; EGFR, epidermal growth factor receptor; IGF-1R, insulin-like growth factor 1 receptor; miRNA, microRNA.

to lymph node metastasis and poor prognosis in patients with lung adenocarcinoma (77). ANRIL is overexpressed in NSCLC tissues and cell lines and elevated ANRIL levels are correlated with poor prognosis in NSCLC patients (74). ANRIL can be found in the plasma of NSCLC patients and acts as an extremely sensitive diagnostic tool with an area under ROC curve (AUC) value of 0.798 (113). Circulating ANRIL expression may be used as a predictor in the early diagnosis of NSCLC (113). Similarly, SOX2OT is upregulated in serum samples of NSCLC and its expression is significantly associated with the overall survival (OS) rate of lung cancer patients (114). Several studies have reported overexpression of MALAT1 in tumor tissue as well as peripheral blood of NSCLC patients (115-118). Weber et al (119) found that MALAT1 expression in the peripheral blood of NSCLC patients was higher compared with healthy controls and was characterized by high specificity and sufficient sensitivity $(A U C=0.79)$. Similarly, Zhang et al (120) indicated that abundant expression of serum exosomal MALAT1 in NSCLC patients was positively associated with tumor stage and lymph node metastasis, suggesting that MALAT1 can act as a tumor biomarker for prognosis and diagnosis in NSCLC. 
Furthermore, Sun et al (121) analyzed 113 cases of NSCLC tissue samples and found that expression of BANCR was remarkably decreased in NSCLC patients with shorter survival time. Similarly, the lncRNA MIR22HG was significantly downregulated in lung cancer compared with normal tissues, and low expression was correlated with poor survival of the patients (61). Liang et al (122) examined a total of 123 human blood sample, which included blood from 90 NSCLC patients and 33 healthy controls prior to surgery and therapy. The levels of GAS5 were notably downregulated in the plasma of NSCLC patients. Of note, the expression levels of GAS5 were associated with $82.2 \%$ sensitivity and $72.7 \%$ specificity via ROC analysis. Moreover, combination of the GAS5 with the carcinoembryonic antigen marker had a higher AUC of 0.909 (95\% confidence interval, 0.857-0.962; P 0.0001) (122). Tantai et al found that compared to a single lncRNA, the combination of the lncRNAs X-inactive specific transcript (XIST) and HIF-1 $\alpha$ antisense RNA 1 (HIF1A-AS1) was also a prospective marker for the diagnosis of NSCLC with an AUC of 0.931 via ROC analysis (123). A study on SPRY4-IT1, ANRIL and nuclear enriched abundant transcript 1 (NEAT1) demonstrated that the combination was a significant marker in the diagnosis of lung cancer $(\mathrm{AUC}=0.876)(113)$.

\section{Conclusion and perspectives}

Emerging substantial research has confirmed that abnormally regulated lncRNAs have crucial roles in the malignant biology of lung cancer. However, available information about lncRNA dysregulation mechanisms in lung cancer remain limited. Further research into the mechanisms by which smoking and air pollution regulate lncRNA expression and by which IncRNAs affect lung cancer initiation and progression will provide valuable information to improve our understanding of lung cancer.

lncRNAs demonstrate diverse and dynamic functions depending on their subcellular localization and interacting molecules. At present, lncRNA remains a poorly understood genomic product; especially their functions in the nucleus as chromatin architecture regulators are unclear. In the future, the construction of a lncRNA-mediated gene expression network and associated signaling pathway network will further reveal the function and molecular mechanisms of lncRNA in proliferation, metastasis, and therapeutic response of lung cancer.

IncRNA-specific expression patterns in cancer subtypes and their stability in body fluid provides a valuable choice as biomarkers for lung cancer. Existing studies of lncRNAs as biomarkers in lung cancer have laid the foundation for clinical application, but require further wider screening and validation in large cohorts. Such studies will further elucidate the potential of IncRNAs as diagnostic markers and treatment targets for lung cancer.

\section{Acknowledgements}

Not applicable.

\section{Funding}

This study was supported by grants from the Overseas Expertise Introduction Project for Discipline Innovation
(111 project, grant no. 111-2-12), the National Natural Science Foundation of China (grant no. 81602030) and the Hunan Province Natural Sciences Foundation of China (grant nos. 2019JJ40395, 2019JJ40436 and 2019JJ40161).

\section{Availability of data and materials}

All data generated or analyzed during this study are included in this published article.

\section{Authors' contributions}

ZL designed and revised the manuscript. LJ wrote the manuscript and drew figures. RW collected the related literature and created the tables. All the authors read and approved the final manuscript.

\section{Ethics approval and consent to participate}

Not applicable.

\section{Patient consent for publication}

Not applicable.

\section{Competing interests}

The authors declare that they have no competing interests.

\section{References}

1. Siegel RL, Miller KD and Jemal A: Cancer statistics, 2018. CA Cancer J Clin 68: 7-30, 2018.

2. Cheng TY, Cramb SM, Baade PD, Youlden DR, Nwogu C and Reid ME: The International epidemiology of lung cancer: Latest trends, disparities, and tumor characteristics. J Thorac Oncol 11: 1653-1671, 2016.

3. Behera M, Owonikoko TK, Gal AA, Steuer CE, Kim S, Pillai RN, Khuri FR, Ramalingam SS and Sica GL: Lung adenocarcinoma staging using the 2011 IASLC/ATS/ERS classification: A pooled analysis of adenocarcinoma in situ and minimally invasive adenocarcinoma. Clin Lung Cancer 17: e57-e64, 2016.

4. Chen Z, Fillmore CM, Hammerman PS, Kim CF and Wong KK: Non-small-cell lung cancers: A heterogeneous set of diseases. Nat Rev Cancer 14: 535-546, 2014.

5. Xue K, Li FF, Chen YW, Zhou YH and He J: Body mass index and the risk of cancer in women compared with men: A meta-analysis of prospective cohort studies. Eur J Cancer Prev 26: 94-105, 2016.

6. de Groot PM, Wu CC, Carter BW and Munden RF: The epidemiology of lung cancer. Transl Luna Cancer Res 7: 220-233, 2018.

7. Siegel RL, Miller KD and Jemal A: Cancer statistics, 2017. CA Cancer J Clin 67: 7-30, 2017.

8. Malhotra J, Malvezzi M, Negri E, La Vecchia C and Boffetta P: Risk factors for lung cancer worldwide. Eur Respir J 48: 889-902, 2016.

9. Cabili MN, Trapnell C, Goff L, Koziol M, Tazon-Vega B, Regev A and Rinn JL: Integrative annotation of human large intergenic noncoding RNAs reveals global properties and specific subclasses. Genes Dev 25: 1915-1927, 2011.

10. Marchese FP, Raimondi I and Huarte M: The multidimensional mechanisms of long noncoding RNA function. Genome Biol 18: 206, 2017.

11. Sun Q, Hao Q and Prasanth KV: Nuclear long noncoding RNAs: Key regulators of gene expression. Trends Genet 34: 142-157, 2018.

12. Huarte M: The emerging role of lncRNAs in cancer. Nat Med 21: 1253-1261, 2015. 
13. Lin $\mathrm{C}$ and Yang L: Long noncoding RNA in cancer: Wiring signaling circuitry. Trends Cell Biol 28: 287-301, 2018.

14. Ding X, Zhang S, Li X, Feng C, Huang Q, Wang S, Wang S, $\mathrm{Xia} \mathrm{W}$, Yang F, Yin R, et al: Profiling expression of coding genes, long noncoding RNA, and circular RNA in lung adenocarcinoma by ribosomal RNA-depleted RNA sequencing. FEBS Open Bio 8: 544-555, 2018.

15. Tang RX, Chen WJ, He RQ, Zeng JH, Liang L, Li SK, Ma J, Luo DZ and Chen G: Identification of a RNA-Seq based prognostic signature with five lncRNAs for lung squamous cell carcinoma. Oncotarget 8: 50761-50773, 2017.

16. Tian X, Zhang H, Zhang B, Zhao J, Li T and Zhao Y: Microarray expression profile of long non-coding RNAs in paclitaxel-resistan human lung adenocarcinoma cells. Oncol Rep 38: 293-300, 2017.

17. Yang J, Lin J, Liu T, Chen T, Pan S, Huang W and Li S: Analysis of lncRNA expression profiles in non-small cell lung cancers (NSCLC) and their clinical subtypes. Lung Cancer 85: 110-115, 2014.

18. Peng F, Wang R, Zhang Y, Zhao Z, Zhou W, Chang Z, Liang H, Zhao W, Qi L, Guo Z and Gu Y: Differential expression analysis at the individual level reveals a lncRNA prognostic signature for lung adenocarcinoma. Mol Cancer 16: 98, 2017

19. Gibb EA, Warren RL, Wilson GW, Brown SD, Robertson GA, Morin GB and Holt RA: Activation of an endogenous retrovirus-associated long non-coding RNA in human adenocarcinoma. Genome Med 7: 22, 2015.

20. Kaplan R, Luettich K, Heguy A, Hackett NR, Harvey BG and Crystal RG: Monoallelic up-regulation of the imprinted H19 gene in airway epithelium of phenotypically normal cigarette smokers. Cancer Res 63: 1475-1482, 2003

21. Chen B, Yu M, Chang Q, Lu Y, Thakur C, Ma D, Yi Z and Chen F: Mdig de-represses H19 large intergenic non-coding RNA (lincRNA) by down-regulating H3K9me3 and heterochromatin. Oncotarget 4: 1427-1437, 2013

22. Fu Y, Wang W, Li X, Liu Y, Niu Y, Zhang B, Nie J, Pan B, Wang R and Yang J: lncRNA H19 interacts with S-adenosylhomocysteine hydrolase to regulate LINE-1 Methylation in human lung-derived cells exposed to Benzo[a]pyrene. Chemosphere 207: 84-90, 2018.

23. Thai P, Statt S, Chen CH, Liang E, Campbell $\mathrm{C}$ and $\mathrm{Wu} \mathrm{R}$ : Characterization of a novel long noncoding RNA, SCAL1, induced by cigarette smoke and elevated in lung cancer cell lines. Am J Respir Cell Mol Biol 49: 204-211, 2013.

24. Hu L, Tang J, Huang X, Zhang T and Feng X: Hypoxia exposure upregulates MALAT-1 and regulates the transcriptional activity of PTB-associated splicing factor in A549 lung adenocarcinoma cells. Oncol Lett 16: 294-300, 2018.

25. Zhou C, Ye L, Jiang C, Bai J, Chi Y and Zhang H: Long noncoding RNA HOTAIR, a hypoxia-inducible factor-1 $\alpha$ activated driver of malignancy, enhances hypoxic cancer cell proliferation, migration, and invasion in non-small cell lung cancer. Tumour Biol 36 9179-9188, 2015

26. Guo F, Guo L, Li Y, Zhou Q and Li Z: MALAT1 is an oncogenic long non-coding RNA associated with tumor invasion in non-small cell lung cancer regulated by DNA methylation. Int J Clin Exp Pathol 8: 15903-15910, 2015.

27. Khaitan D, Dinger ME, Mazar J, Crawford J, Smith MA, Mattick JS and Perera RJ: The melanoma-upregulated long noncoding RNA SPRY4-IT1 modulates apoptosis and invasion. Cancer Res 71: 3852-3862, 2011.

28. Sun M, Liu XH, Lu KH, Nie FQ, Xia R, Kong R, Yang JS, Xu TP Liu YW, Zou YF, et al: EZH2-mediated epigenetic suppression of long noncoding RNA SPRY4-IT1 promotes NSCLC cell proliferation and metastasis by affecting the epithelial-mesenchymal transition. Cell Death Dis 5: e1298, 2014.

29. Wen X, Han XR, Wang YJ, Fan SH, Zhuang J, Zhang ZF, Shan Q, Li MQ, Hu B, Sun CH, et al: Effects of long noncoding RNA SPRY4-IT1-mediated EZH2 on the invasion and migration of lung adenocarcinoma. J Cell Biochem 119: 1827-1840, 2018.

30. Zhai N, Xia Y, Yin R, Liu J and Gao F: A negative regulation loop of long noncoding RNA HOTAIR and p53 in non-small-cell lung cancer. Onco Targets Ther 9: 5713-5720, 2016.

31. Hung T, Wang Y, Lin MF, Koegel AK, Kotake Y, Grant GD, Horlings HM, Shah N, Umbricht C, Wang P, et al: Extensive and coordinated transcription of noncoding RNAs within cell-cycle promoters. Nat Genet 43: 621-629, 2011

32. Han L, Zhang EB, Yin DD, Kong R, Xu TP, Chen WM, Xia R, Shu YQ and De W: Low expression of long noncoding RNA PANDAR predicts a poor prognosis of non-small cell lung cancer and affects cell apoptosis by regulating Bcl-2. Cell Death Dis 6: e1665, 2015.
33. Barsyte-Lovejoy D, Lau SK, Boutros PC, Khosravi F, Jurisica I, Andrulis IL, Tsao MS and Penn LZ: The c-Myc oncogene directly induces the H19 noncoding RNA by allele-specific binding to potentiate tumorigenesis. Cancer Res 66: 5330-5337, 2006.

34. Lu Y, Zhou X, Xu L, Rong C, Shen C and Bian W: Long noncoding RNA ANRIL could be transactivated by c-Myc and promote tumor progression of non-small-cell lung cancer. Onco Targets Ther 9: 3077-3084, 2016.

35. Huang T, Wang G, Yang L, Peng B, Wen Y, Ding G and Wang Z Transcription Factor YY1 modulates lung cancer progression by activating lncRNA-PVT1. DNA Cell Biol 36: 947-958, 2017

36. Wan L, Sun M, Liu GJ, Wei CC, Zhang EB, Kong R, Xu TP, Huang MD and Wang ZX: Long noncoding RNA PVT1 promotes non-small cell lung cancer cell proliferation through epigenetically regulating LATS 2 expression. Mol Cancer Ther 15: 1082-1094, 2016

37. Li S, Ma F, Jiang K, Shan H, Shi M and Chen B: Long non-coding RNA metastasis-associated lung adenocarcinoma transcript 1 promotes lung adenocarcinoma by directly interacting with specificity protein 1. Cancer Sci 109: 1346-1356, 2018.

38. Jen J, Tang YA, Lu YH, Lin CC, Lai WW and Wang YC: Oct4 transcriptionally regulates the expression of long non-coding RNAs NEAT1 and MALAT1 to promote lung cancer progression. Mol Cancer 16: 104, 2017.

39. Guo F, Jiao F, Song Z, Li S, Liu B, Yang H, Zhou Q and Li Z: Regulation of MALAT1 expression by TDP43 controls the migration and invasion of non-small cell lung cancer cells in vitro. Biochem Biophys Res Commun 465: 293-298, 2015.

40. Li S, Mei Z, Hu HB and Zhang X: The IncRNA MALAT1 contributes to non-small cell lung cancer development via modulating miR-124/STAT3 axis. J Cell Physiol 233: 6679-6688, 2018.

41. Tang Y, Xiao G, Chen Y and Deng Y: 1ncRNA MALAT1 promotes migration and invasion of non-small-cell lung cancer by targeting miR-206 and activating Akt/mTOR signaling. Anticancer Drugs 29: 725-735, 2018.

42. Tripathi V, Ellis JD, Shen Z, Song DY, Pan Q, Watt AT, Freier SM, Bennett CF, Sharma A, Bubulya PA, et al: The nuclear-retained noncoding RNA MALAT1 regulates alternative splicing by modulating SR splicing factor phosphorylation. Mol Cell 39: 925-938, 2010.

43. Tano K, Onoguchi-Mizutani R, Yeasmin F, Uchiumi F, Suzuki Y, Yada $\mathrm{T}$ and Akimitsu N: Identification of minimal p53 promoter region regulated by MALAT1 in human lung adenocarcinoma Cells. Front Genet 8: 208, 2018.

44. Ma J, Wu K, Liu K and Miao R: Effects of MALAT1 on proliferation and apo-ptosis of human non-small cell lung cancer A549 cells in vitro and tumor xenograft growth in vivo by modulating autophagy. Cancer Biomark 22: 63-72, 2018.

45. Tsai MC, Manor O, Wan Y, Mosammaparast N, Wang JK, Lan F, Shi Y, Segal E and Chang HY: Long noncoding RNA as modular scaffold of histone modification complexes. Science 329: 689-693, 2010

46. Wang R, Chen X, Xu T, Xia R, Han L, Chen W, De W and Shu Y: miR-326 regulates cell proliferation and migration in lung cancer by targeting phox $2 \mathrm{a}$ and is regulated by HOTAIR. Am J Cancer Res 6: 173-186, 2016.

47. Feng $\mathrm{L}$, Xie $\mathrm{Y}$, Zhang $\mathrm{H}$ and $\mathrm{Wu} \mathrm{Y}$ : miR-107 targets cyclin-dependent kinase 6 expression, induces cell cycle G1 arrest and inhibits invasion in gastric cancer cells. Med Oncol 29: 856-863, 2012.

48. Cui J, Mo J, Luo M, Yu Q, Zhou S, Li T, Zhang Y and Luo W: c-Myc-activated long non-coding RNA H19 downregulates miR-107 and promotes cell cycle progression of non-small cell lung cancer. Int J Clin Exp Pathol 8: 12400-12409, 2015.

49. Zhang E, Li W, Yin D, De W, Zhu L, Sun S and Han L: c-Myc-regulated long non-coding RNA H19 indicates a poor prognosis and affects cell proliferation in non-small-cell lung cancer. Tumour Biol 37: 4007-4015, 2016.

50. Huang Z, Lei W, Hu HB, Zhang H and Zhu Y: H19 promotes non-small-cell lung cancer (NSCLC) development through STAT3 signaling via sponging miR-17. J Cell Physiol 233: 6768-6776, 2018

51. Zhang Q, Li X, Li X, Li X and Chen Z: lncRNA H19 promotes epithelial-mesenchymal transition (EMT) by targeting miR-484 in human lung cancer cells. J Cell Biochem 119: 4447-4457, 2018.

52. Ren J, Fu J, Ma T, Yan B, Gao R, An Z and Wang D: lncRNA H19-elevated LIN28B promotes lung cancer progression through sequestering miR-196b. Cell Cycle 17: 1372-1380, 2018. 
53. Chen Z, Li JL, Lin S, Cao C, Gimbrone NT, Yang R, Fu DA, Carper MB, Haura EB, Schabath MB, et al: cAMP/CREB-regulated LINC00473 marks LKB1-inactivated lung cancer and mediates tumor growth. J Clin Invest 126: 2267-2279, 2016

54. Li J, Li P, Zhao W, Yang R, Chen S, Bai Y, Dun S, Chen X, Du Y, Wang Y, et al: Expression of long non-coding RNA DLX6-AS1 in lung adenocarcinoma. Cancer Cell Int 15: 48, 2015.

55. Naemura M, Murasaki C, Inoue $\mathrm{Y}$, Okamoto $\mathrm{H}$ and Kotake $\mathrm{Y}$ : Long noncoding RNA ANRIL regulates proliferation of non-small cell lung cancer and cervical cancer cells. Anticancer Res 35: 5377-5382, 2015.

56. Nie FQ, Sun M, Yang JS, Xie M, Xu TP, Xia R, Liu YW, Liu XH, Zhang EB, Lu KH and Shu YQ: Long noncoding RNA ANRIL promotes non-small cell lung cancer cell proliferation and inhibits apoptosis by silencing KLF2 and P21 expression. Mol Cancer Ther 14: 268-277, 2015.

57. Hou Z, Zhao W, Zhou J, Shen L, Zhan P, Xu C, Chang C, Bi H, Zou J, Yao X, et al: A long noncoding RNA Sox2ot regulates lung cancer cell proliferation and is a prognostic indicator of poor survival. Int J Biochem Cell Biol 53: 380-388, 2014

58. Flockhart RJ, Webster DE, Qu K, Mascarenhas N, Kovalski J, Kretz $\mathrm{M}$ and Khavari PA: BRAFV600E remodels the melanocyte transcriptome and induces BANCR to regulate melanoma cell migration. Genome Res 22: 1006-1014, 2012.

59. Jiang W, Zhang D, Xu B, Wu Z, Liu S, Zhang L, Tian Y, Han X and Tian D: Long non-coding RNA BANCR promotes proliferation and migration of lung carcinoma via MAPK pathways. Biomed Pharmacother 69: 90-95, 2015.

60. Zhao JM, Cheng W, He XG, Liu YL, Wang FF and Gao YF: Long non-coding RNA PICART1 suppresses proliferation and promotes apoptosis in lung cancer cells by inhibiting JAK2/STAT3 signaling. Neoplasma 65: 779-789, 2018.

61. Su W, Feng S, Chen X, Yang X, Mao R, Guo C, Wang Z, Thomas DG, Lin J, Reddy RM, et al: Silencing of long noncoding RNA MIR22HG triggers cell Survival/Death signaling via oncogenes YBX1, MET, and p21 in lung cancer. Cancer Res 78 : 3207-3219, 2018.

62. Mondal T, Rasmussen M, Pandey GK, Isaksson A and Kanduri C: Characterization of the RNA content of chromatin. Genome Res 20: 899-907, 2010.

63. Wei MM, Zhou YC, Wen ZS, Zhou B, Huang YC, Wang GZ, Zhao XC, Pan HL, Qu LW, Zhang J, et al: Long non-coding RNA stabilizes the Y-box-binding protein 1 and regulates the epidermal growth factor receptor to promote lung carcinogenesis. Oncotarget 7: 59556-59571, 2016.

64. Liu M, Sun W, Liu Y and Dong X: The role of lncRNA MALAT1 in bone metastasis in patients with non-small cell lung cancer. Oncol Rep 36: 1679-1685, 2016.

65. Gutschner T, Hammerle M, Eissmann M, Hsu J, Kim Y, Hung G, Revenko A, Arun G, Stentrup M, Gross M, et al: The noncoding RNA MALAT1 is a critical regulator of the metastasis phenotype of lung cancer cells. Cancer Res 73: 1180-1189, 2013.

66. Li J, Wang J, Chen Y, Li S, Jin M, Wang H, Chen Z and Yu W: IncRNA MALAT1 exerts oncogenic functions in lung adenocarcinoma by targeting miR-204. Am J Cancer Res 6: 1099-1107, 2016.

67. Jiang C, Yang Y, Yang Y, Guo L, Huang J, Liu X, Wu C and Zou J: Long noncoding RNA (lncRNA) HOTAIR affects tumorigenesis and metastasis of non-small cell lung cancer by upregulating miR-613. Oncol Res 26: 725-734, 2018

68. Wang R, Yan B, Li Z, Jiang Y, Mao C, Wang X and Zhou X: Long non-coding RNA HOX transcript antisense RNA promotes expression of 14-3-3 $\sigma$ in non-small cell lung cancer. Exp Ther Med 14: 4503-4508, 2017

69. Liu XH, Liu ZL, Sun M, Liu J, Wang ZX and De W: The long non-coding RNA HOTAIR indicates a poor prognosis and promotes metastasis in non-small cell lung cancer. BMC cancer 13: 464, 2013.

70. Ono H, Motoi N, Nagano H, Miyauchi E, Ushijima M Matsuura M, Okumura S, Nishio M, Hirose T, Inase $N$ and Ishikawa Y: Long noncoding RNA HOTAIR is relevant to cellular proliferation, invasiveness, and clinical relapse in small-cell lung cancer. Cancer Med 3: 632-642, 2014.

71. Wang R, Shi Y, Chen L, Jiang Y, Mao C, Yan B, Liu S, Shan B, Tao Y and Wang X: Theratio of FoxA1 to FoxA2 in lung adenocarcinoma is regulated by lncRNA HOTAIR and chromatin remodeling factor LSH. Sci Rep 5: 17826, 2015.

72. Guo D, Wang Y, Ren K and Han X: Knockdown of IncRNA PVT1 inhibits tumorigenesis in non-small-cell lung cancer by regulating miR-497 expression. Exp Cell Res 362: 172-179, 2018
73. Chen W, Zhu H, Yin L, Wang T, Wu J, Xu J, Tao H, Liu J and He X: lncRNA-PVT1 facilitates invasion through upregulation of MMP9 in nonsmall cell lung cancer cell. DNA Cell Biol 36: 787-793, 2017.

74. Lin L, Gu ZT, Chen WH and Cao KJ: Increased expression of the long non-coding RNA ANRIL promotes lung cancer cell metastasis and correlates with poor prognosis. Diagn Pathol 10: 14, 2015.

75. Li Z, Yu X and Shen J: ANRIL: A pivotal tumor suppressor long non-coding RNA in human cancers. Tumour Biol 37: 5657-5661, 2016.

76. Yu T, Zhao Y, Hu Z, Li J, Chu D, Zhang J, Li Z, Chen B, Zhang X, Pan $\mathrm{H}$, et al: Metalnc9 facilitates lung cancer metastasis via a PGK1-activated AKT/mTOR pathway. Cancer Res 77: 5782-5794, 2017.

77. Zhang L, Zhou XF, Pan GF and Zhao JP: Enhanced expression of long non-coding RNA ZXF1 promoted the invasion and metastasis in lung adenocarcinoma. Biomed Pharmacother 68 401-407, 2014

78. Ge X, Li GY, Jiang L, Jia L, Zhang Z, Li X, Wang R, Zhou M, Zhou Y, Zeng Z, et al: Long noncoding RNA CAR10 promotes lung adenocarcinoma metastasis via miR-203/30/SNAI axis. Oncogene 38: 3061-3076, 2019.

79. Falzone L, Salomone S and Libra M: Evolution of cancer pharmacological treatments at the turn of the third millennium. Front Pharmacol 9: 1300, 2018.

80. Sun YW, Xu J, Zhou J and Liu WJ: Targeted drugs for systemic therapy of lung cancer with brain metastases. Oncotarget 9 $5459-5472,2017$

81. Yang CJ, Hung JY, Tsai MJ, Wu KL, Liu TC, Chou SH, Lee JY, Hsu JS, Huang MS and Chong IW: The salvage therapy in lung adenocarcinoma initially harbored susceptible EGFR mutation and acquired resistance occurred to the first-line gefitinib and second-line cytotoxic chemotherapy. BMC Pharmacol Toxicol 18: 21, 2017.

82. Mitsudomi T: Advances in target therapy for lung cancer. Jpn J Clin Oncol 40: 101-106, 2010.

83. Konieczna A, Novakova V, Medalova J, Erceg S and Klabusay M: Thiazolidinediones regulate the level of ABC transporters expression on lung cancer cells. Klin Onkol 28: 431-438, 2015

84. Gao Y, Li W, Liu X, Gao F and Zhao X: Reversing effect and mechanism of soluble resistance-related calcium-binding protein on multidrug resistance in human lung cancer A549/DDP cells Mol Med Rep 11: 2118-2124, 2015

85. Patel NR, Pattni BS, Abouzeid AH and Torchilin VP: Nanopreparations to overcome multidrug resistance in cancer. Adv Drug Deliv Rev 65: 1748-1762, 2013.

86. Fang Z, Chen W, Yuan Z, Liu X and Jiang H: lncRNA-MALAT1 contributes to the cisplatin-resistance of lung cancer by upregulating MRP1 and MDR1 via STAT3 activation. Biomed Pharmacother 101: 536-542, 2018.

87. Liu MY, Li XQ, Gao TH, Cui Y, Ma N, Zhou Y and Zhang GJ: Elevated HOTAIR expression associated with cisplatin resistance in non-small cell lung cancer patients. J Thorac Dis 8: 3314-3322, 2016.

88. Wang Q, Cheng N, Li X, Pan H, Li C, Ren S, Su C, Cai W, Zhao C, Zhang L and Zhou C: Correlation of long non-coding RNA H19 expression with cisplatin-resistance and clinical outcome in lung adenocarcinoma. Oncotarget 8: 2558-2567, 2017.

89. Liu J, Wan L, Lu K, Sun M, Pan X, Zhang P, Lu B, Liu G and Wang Z: The long noncoding RNA MEG3 contributes to cisplatin resistance of human lung adenocarcinoma. PLoS One 10: $\mathrm{e} 0114586,2015$.

90. Yang Y, Li H, Hou S, Hu B, Liu J and Wang J: The noncoding RNA expression profile and the effect of lncRNA AK126698 on cisplatin resistance in non-small-cell lung cancer cell. PLoS One 8: e65309,2013.

91. Chen W, Zhao W, Zhang L, Wang L, Wang J, Wan Z, Hong Y and Yu L: MALAT1-miR-101-SOX9 feedback loop modulates the chemo-resistance of lung cancer cell to DDP via Wnt signaling pathway. Oncotarget 8: 94317-94329, 2017.

92. Wang H, Wang L, Zhang G, Lu C, Chu H, Yang R and Zhao G: MALAT1/miR-101-3p/MCL1 axis mediates cisplatin resistance in lung cancer. Oncotarget 9: 7501-7512, 2017.

93. Liu Z, Sun M, Lu K, Liu J, Zhang M, Wu W, De W, Wang Z and Wang R: The long noncoding RNA HOTAIR contributes to cisplatin resistance of human lung adenocarcinoma cells via downregualtion of $\mathrm{p} 21$ (WAF1/CIP1) expression. PLoS One 8: e77293,2013. 
94. Rhee I, Bachman KE, Park BH, Jair KW, Yen RW, Schuebel KE, Cui H, Feinberg AP, Lengauer C, Kinzler KW, et al: DNMT1 and DNMT3b cooperate to silence genes in human cancer cells. Nature 416: 552-556, 2002.

95. Fang S, Gao H, Tong Y, Yang J, Tang R, Niu Y, Li M and Guo L: Long noncoding RNA-HOTAIR affects chemoresistance by regulating HOXA1 methylation in small cell lung cancer cells. Lab Invest 96: 60-68, 2016.

96. Kris MG, Natale RB, Herbst RS, Lynch TJ Jr, Prager D, Belani CP, Schiller JH, Kelly K, Spiridonidis H, Sandler A, et al: Efficacy of gefitinib, an inhibitor of the epidermal growth factor receptor tyrosine kinase, in symptomatic patients with non-small cell lung cancer: A randomized trial. JAMA 290: 2149-2158, 2003.

97. Wheler J, Falchook G, Tsimberidou AM, Hong D, Naing A, Piha-Paul S, Chen SS, Heymach J, Fu S, Stephen B, et al: Revisiting clinical trials using EGFR inhibitor-based regimens in patients with advanced non-small cell lung cancer: A retrospective analysis of an MD Anderson Cancer Center phase I population. Oncotarget 4: 772-784, 2013.

98. Chang YS, Choi CM and Lee JC: Mechanisms of epidermal growth factor receptor tyrosine kinase inhibitor resistance and strategies to overcome resistance in lung adenocarcinoma. Tuberc Respir Dis (Seoul) 79: 248-256, 2016.

99. Cheng N, Li X, Zhao C, Ren S, Chen X, Cai W, Zhao M, Zhang Y, Li J, Wang Q and Zhou C: Microarray expression profile of long non-coding RNAs in EGFR-TKIs resistance of human non-small cell lung cancer. Oncol Rep 33: 833-839, 2015.

100. Liu Y, Jiang H, Zhou H, Ying X, Wang Z, Yang Y, Xu W, He X and $\mathrm{Li}$ Y: Lentivirus-mediated silencing of HOTAIR lncRNA restores gefitinib sensitivity by activating Bax/caspase-3 and suppressing TGF- $\alpha /$ EGFR signaling in lung adenocarcinoma. Oncol Lett 15: 2829-2838, 2018.

101. Cheng N, Cai W, Ren S, Li X, Wang Q, Pan H, Zhao M, Li J, Zhang Y, Zhao C, et al: Long non-coding RNA UCA1 induces non-T790M acquired resistance to EGFR-TKIs by activating the AKT/mTOR pathway in EGFR-mutant non-small cell lung cancer. Oncotarget 6: 23582-23593, 2015.

102. Dong S, Qu X, Li W, Zhong X, Li P, Yang S, Chen X, Shao M and Zhang L: The long non-coding RNA, GAS5, enhances gefitinib-induced cell death in innate EGFR tyrosine kinase inhibitor-resistant lung adenocarcinoma cells with wide-type EGFR via downregulation of the IGF-1R expression. J Hematol Oncol 8: 43, 2015.

103. Yang Y, Jiang C, Yang Y, Guo L, Huang J, Liu X, Wu C and Zou J: Silencing of lncRNA-HOTAIR decreases drug resistance of Non-small cell lung cancer cells by inactivating autophagy via suppressing the phosphorylation of ULK1. Biochem Biophys Res Commun 497: 1003-1010, 2018.

104. Chen J, Shen Z, Zheng Y, Wang S and Mao W: Radiotherapy induced Lewis lung cancer cell apoptosis via inactivating $\beta$-catenin mediated by upregulated HOTAIR. Int J Clin Exp Pathol 8: 7878-7886, 2015.

105. Wu D, Li Y, Zhang H and Hu X: Knockdown of lncrna PVT1 enhances radiosensitivity in Non-small cell lung cancer by sponging Mir-195. Cell Physiol Biochem 42: 2453-2466, 2017.

106. Chen JX, Chen M, Zheng YD, Wang SY and Shen ZP Up-regulation of BRAF activated non-coding RNA is associated with radiation therapy for lung cancer. Biomed Pharmacother 71 79-83, 2015

107. Loewen G, Jayawickramarajah J, Zhuo Y and Shan B: Functions of lncRNA HOTAIR in lung cancer. J Hematol Oncol 7: 90, 2014.

108. Nakagawa T, Endo H, Yokoyama M, Abe J, Tamai K, Tanaka N, Sato I, Takahashi S, Kondo T and Satoh K: Large noncoding RNA HOTAIR enhances aggressive biological behavior and is associated with short disease-free survival in human non-small cell lung cancer. Biochem Biophys Res Commun 436: 319-324, 2013.
109. Li N, Wang Y, Liu X, Luo P, Jing W, Zhu M and Tu J: Identification of Circulating long noncoding RNA HOTAIR as a novel biomarker for diagnosis and monitoring of Non-small cell lung cancer. Technol Cancer Res Treat: Jan 1, 2017 doi: 10.1177/1533034617723754 (Epub ahead of print).

110. Wu X, Ruan L, Yang Y and Mei Q: Identification of crucial regulatory relationships between long non-coding RNAs and protein-coding genes in lung squamous cell carcinoma. Mol Cell Probes 30: 146-152, 2016.

111. Cui D, Yu CH, Liu M, Xia QQ, Zhang YF and Jiang WL: Long non-coding RNA PVT1 as a novel biomarker for diagnosis and prognosis of non-small cell lung cancer. Tumour Biol 37: 4127-4134, 2016.

112. Yang YR, Zang SZ, Zhong CL, Li YX, Zhao SS and Feng XJ: Increased expression of the lncRNA PVT1 promotes tumorigenesis in non-small cell lung cancer. Int J Clin Exp Pathol 7: 6929-6935, 2014.

113. Hu X, Bao J, Wang Z, Zhang Z, Gu P, Tao F, Cui D and Jiang W: The plasma lncRNA acting as fingerprint in non-small-cell lung cancer. Tumour Biol 37: 3497-3504, 2016.

114. Xie Y, Zhang Y, Du L, Jiang X, Yan S, Duan W, Li J, Zhan Y, Wang L, Zhang S, et al: Circulating long noncoding RNA act as potential novel biomarkers for diagnosis and prognosis of non-small cell lung cancer. Mol Oncol 12: 648-658, 2018.

115. Schmidt LH, Spieker T, Koschmieder S, Schaffers S, Humberg J, Jungen D, Bulk E, Hascher A, Wittmer D, Marra A, et al: The long noncoding MALAT-1 RNA indicates a poor prognosis in non-small cell lung cancer and induces migration and tumor growth. J Thorac Oncol 6: 1984-1992, 2011.

116. Ji P, Diederichs S, Wang W, Böing S, Metzger R, Schneider PM, Tidow N, Brandt B, Buerger H, Bulk E, et al: MALAT-1, a novel noncoding RNA, and thymosin beta4 predict metastasis and survival in early-stage non-small cell lung cancer. Oncogene 22: 8031-8041, 2003.

117. Lin L, Li H,Zhu Y, He S and Ge H: Expression of metastasis-associated lung adenocarcinoma transcript 1 long non-coding RNA in vitro and in patients with non-small cell lung cancer. Oncol Lett 15: 9443-9449, 2018.

118. Tian $\mathrm{X}$ and $\mathrm{Xu}$ G: Clinical value of $\operatorname{lncRNA}$ MALAT1 as a prognostic marker in human cancer: Systematic review and meta-analysis. BMJ Open 5: e008653, 2015.

119. Weber DG, Johnen G, Casjens S, Bryk O, Pesch B, Jöckel KH, Kollmeier $\mathrm{J}$ and Brüning T: Evaluation of long noncoding RNA MALAT1 as a candidate blood-based biomarker for the diagnosis of non-small cell lung cancer. BMC Res Notes 6: 518, 2013.

120. Zhang R, Xia Y, Wang Z, Zheng J, Chen Y, Li X, Wang Y and Ming H: Serum long non coding RNA MALAT-1 protected by exosomes is up-regulated and promotes cell proliferation and migration in non-small cell lung cancer. Biochem Biophys Res Commun 490: 406-414, 2017.

121. Sun M, Liu XH, Wang KM, Nie FQ, Kong R, Yang JS, Xia R, Xu TP, Jin FY, Liu ZJ, et al: Downregulation of BRAF activated non-coding RNA is associated with poor prognosis for non-small cell lung cancer and promotes metastasis by affecting epithelial-mesenchymal transition. Mol Cancer 13: 68, 2014.

122. Liang W, Lv T, Shi X, Liu H, Zhu Q, Zeng J, Yang W, Yin J and Song Y: Circulating long noncoding RNA GAS5 is a novel biomarker for the diagnosis of nonsmall cell lung cancer. Medicine (Baltimore) 95: e4608, 2016.

123. Tantai J, Hu D, Yang Y and Geng J: Combined identification of long non-coding RNA XIST and HIF1A-AS1 in serum as an effective screening for non-small cell lung cancer. Int J Clin Exp Pathol 8: 7887-7895, 2015.

This work is licensed under a Creative Commons Attribution-NonCommercial-NoDerivatives 4.0 International (CC BY-NC-ND 4.0) License. 